\title{
Falls and cognitive decline in Mexican Americans 75 years and older
}

\author{
This article was published in the following Dove Press journal: \\ Clinical Interventions in Aging \\ 22 April 2014 \\ Number of times this article has been viewed
}

\author{
Anokha Padubidri ${ }^{1,2}$ \\ Soham Al Snih ${ }^{2,3}$ \\ Rafael Samper-Ternent ${ }^{2,4}$ \\ Kyriakos S Markides ${ }^{2,5}$ \\ Kenneth J Ottenbacher ${ }^{2,3}$ \\ Mukaila A Raji ${ }^{2,6}$ \\ 'College of Medicine, Northeast \\ Ohio Medical University, Rootstown, \\ $\mathrm{OH}$, USA; ${ }^{2}$ Sealy Center on Aging, \\ ${ }^{3}$ Division of Rehabilitation Sciences, \\ School of Health Professions, the \\ University of Texas Medical Branch, \\ Galveston, TX, USA; ${ }^{4}$ Department \\ of Internal Medicine, Hospital \\ Universitario San Ignacio, Pontificia \\ Universidad Javeriana, Bogota, \\ Columbia; ${ }^{5}$ Department of Preventive \\ Medicine and Community Health, \\ ${ }^{6}$ Department of Internal Medicine, \\ the University of Texas Medical \\ Branch, Galveston, TX, USA
}

Background: Little is known about long-term emotional and cognitive consequences of falls. We examined the association between falls and subsequent cognitive decline, and tested the hypothesis that depression would mediate any falls-cognition association among cognitively intact Hispanic Elders.

Methods: We used data from the Hispanic Established Population for the Epidemiological Study of the Elderly to examine change in Mini Mental State Examination (MMSE) scores over the 6-year period according to number of falls. All participants $(\mathrm{N}=1,119)$ had MMSE scores $\geq 21$ and complete data on Center for Epidemiologic Studies of Depression Scale, social and demographic factors, medical conditions (diabetes, heart attack, stroke, and hypertension), and hand grip muscle strength.

Results: At baseline, participants' mean age was 80.8 years (range, 74-109), mean education was 6.3 years (range, 0-17), and mean MMSE was 25.2 (range, 21-30). Of the 1,119 participants, $15.8 \%$ experienced one fall and $14.4 \%$ had two or more falls. In mixed model analyses, having two or more falls was associated with greater decline in MMSE score (estimate $=-0.81$, standard error $=0.19, P<0.0001)$ compared to having no fall, after adjusting for age, sex, marital status, and education. The magnitude of the association decreased (estimate $=-0.65$, standard error $=0.19, P=0.0007$ ) when adjustment was made for high depressive symptoms, suggesting a possible mediating effect of depression on the falls-cognition association. Female sex, high level of education, and high performance in hand grip muscle strength were associated with a slower decline in MMSE scores.

Conclusion: Having two or more falls was independently associated with steeper decline in cognition over 6 years, with a possible mediating effect of depression on the falls-cognition association.

Keywords: cognition, depression, elderly

\section{Introduction}

Annually, falls occur in about one third of community-dwelling adults aged 65 and older living in the US. ${ }^{1}$ The physical and functional impacts (fractures, soft-tissue injury, premature institutionalization, and deaths) of falls have been well documented, but little is known about the long-term emotional and cognitive impact of falls. ${ }^{2-6}$ Also, falls, depression, and cognitive impairments frequently coexist in the same patient, raising the possibility of shared risk factors and shared etiology. Preventing falls-related disability requires a good understanding of how experience of falls affects subsequent emotional and cognitive function. Such understanding can inform development of interventions to stem the onset of not only physical disability but any fall-related cognitive disability.

Falls, depression, and cognitive impairment shared common risk factors. ${ }^{3,5,7-12}$ Past studies showed a relationship between cognitive impairment and falls, $3,8,9$ cognitive impairment and depression, ${ }^{10}$ and falls and depression. ${ }^{6,11,12}$ However,
Correspondence: Mukaila A Raji

Division of Geriatrics, Sealy Center on Aging, University of Texas Medical Branch, 30I University Blvd, Galveston, TX 77555-0177, USA

Tel + I 4097721987

Fax +I 4097473585

Email muraji@utmb.edu 
the synergistic relationship among these three syndromes has not been explored in depth. Raji et al found an association between lower scores on the Mini Mental State Examination (MMSE) and high depressive symptomatology in older Mexican Americans. ${ }^{10}$ A later study of the effects of cognitive and emotional status on physical functioning found that having high depression and low cognition was associated with poor physical performance. ${ }^{13}$ In another study of 283 adults aged 60 and older, Biderman et al determined that the common risk factors for falls and depression are poor self-rated health, poor cognitive status, impaired ability to perform activities of daily living, two or more clinic visits in the past month, and slow walking speed. ${ }^{14}$

Another explanation for the complex relationships among falls, depression, and cognitive decline may be due to subsequent events following development of one of the conditions. Evidence supports the hypothesis linking falls to depression and cognitive decline. Falls in older persons have been associated with development of fear of falls, ${ }^{15}$ with a subsequent decrease in levels of physical activity, walking, participation in social activities, and an increase in loneliness and social isolation. ${ }^{15-19}$ Over time, reduced social and physical activity may lead to onset of depression and future cognitive decline. ${ }^{20-22} \mathrm{We}$ wanted to explore this hypothesis further by testing whether, in a group of cognitively intact elders, recurrent falls would be independently associated with faster cognitive decline, and whether presence of depression would at least in part mediate this association. Because of the high prevalence of depressive symptoms and cognitive impairments in older Mexican American adults, ${ }^{11,23,24}$ a fast growing segment of the US population, we wanted to test whether having a fall would trigger social isolation, depression, and subsequent worsening of cognition. To avoid the floor effects of the MMSE, we chose to include only those with normal baseline cognition (MMSE $\geq 21$ ), a cut-off point recommended in populations with low educational attainment. ${ }^{25}$ Mean education of our sample was 6.3 years. Understanding the fall-cognition pathway is key to designing interventions that address all the potential pathways to cognitive and motor disability attributed to falls.

The objectives of our study were two-fold. First, we examined the association of falls versus no falls on subsequent change in cognitive function (using the MMSE) over a 6-year period in a community sample of older Mexican Americans who were initially cognitively normal. Second, because past research has shown an association between depression and cognitive decline, ${ }^{10}$ we tested whether depressive symptoms would have a mediating effect on the association between falls and cognitive change.

\section{Methods}

\section{Sample and procedures}

Data are from the H-EPESE (Hispanic Established Populations for Epidemiologic Studies of the Elderly), an ongoing longitudinal study of Mexican Americans 65 years and older who reside in Texas, Colorado, California, New Mexico, and Arizona, USA. ${ }^{23}$ In-home interviews were conducted of 3,050 participants or their proxy at the beginning of the study (1993-1994). The sampling procedure assured a sample that is generalizable to approximately 500,000 older Mexicans Americans living in the southwest and has been described elsewhere. ${ }^{23}$ Data were collected during home visits by trained interviewers in the language of the subject's choice (Spanish or English). The face-to-face interviews included questionnaires, interviews, and physical assessments.

The present study used participants interviewed in 2004-2005 (wave 5), 2007-2008 (wave 6), and 2010-2011 (wave 7). Wave 5 in this study is considered as baseline with two follow-ups (wave 6 and wave 7). We excluded those with a MMSE score $<21(\mathrm{~N}=681)^{25}$ because we were interested in examining how falls and high depressive symptoms influenced changes in cognitive function in those with normal or high cognition. Also, we excluded those with missing information on the MMSE (N=199). Participants with missing information on the MMSE and those with MMSE $<21$ were significantly more likely to be older, have low level of education, perform lower in hand grip strength, report less hypertension, and report more stroke, hip fracture, high depressive symptoms, and falls compared with those with MMSE $\geq 21$. After excluding participants with an MMSE score $<21$ at baseline and those with missing data on MMSE, fall status, and all covariates, the final sample consisted of 1,119 participants. Subjects excluded were significantly more likely to be older, unmarried, and to have reported more hypertension, stroke, hip fractures, and high depressive symptoms. They were also more likely to have less education, a lower MMSE score, and have had two or more falls.

\section{Measures}

\section{Fall status}

Fall status was established by asking the participants at each interview the following question: "During the last 12 months, how many times did you fall and land on the floor or ground?" Fall status was categorized as having no falls, having one fall, or having two or more falls. 


\section{Cognitive function}

Cognitive function was assessed with the MMSE. Scored on a 30-point scale, the MMSE screens for difficulties in episodic memory, orientation, working memory, naming, language, and image copying. ${ }^{26,27}$ Higher scores indicate better cognition. Interviewers were thoroughly trained in administering and scoring the MMSE, through both workshops and videotaped instruction. The English and Spanish versions of the MMSE were adopted from the Diagnostic Interview Scale used in prior community surveys. ${ }^{28}$ This Spanish version of the MMSE has met standard criteria for development of translated tests, including formal translation, back-translation, and consensus by committee for final item content. Additionally, the Spanish MMSE has been successfully used in community surveys of Mexican Americans. ${ }^{29}$

\section{Covariates}

Baseline sociodemographic variables included age, sex, marital status, and years of education. The presence of various medical conditions was determined with a series of questions asking participants if a doctor had ever told them that they had diabetes, heart attack, stroke, or hypertension. Depressive symptomatology was measured with the Center for Epidemiologic Studies Depression Scale. ${ }^{30}$ This scale consists of 20 items that ask how often specific symptoms were experienced during the past week; responses were scored on a 4-point scale (ranging from rarely or none of the time to most or all of the time: $0,1,2,3)$ with potential total scores ranging $0-60$. Alpha reliability with these data was 0.89 . As is common in the literature, we consider persons scoring 16 or over to experience high depressive symptomatology..$^{10,11,30}$

\section{Statistical analysis}

Chi-square, analysis of variance, and post hoc Tukey's tests were used to examine the distribution of covariates for participants by fall status at baseline. General linear mixed models using the MIXED procedure in SAS (SAS Institute, Inc., Cary, NC, USA) were used to examine the factors associated with decline in cognitive function over a 6-year period as a function of fall status. All variables were analyzed as timedependent covariates (potential to change as time progresses) except age, sex, and education. The mixed model was chosen for analysis because it best handles unbalanced data, allowing for modeling of both the time-dependent change in variables as well as the time-dependent change in the magnitude of association between variables. In addition, because H-EPESE data comprised repeated measures over 6 years, mixed models allowed more flexibility in modeling the effects of time on outcome. ${ }^{31,32}$ Three mixed models were constructed to test the relationship between fall status and cognitive decline over a 6-year period. Model 1 included time, age, sex, marital status, years of formal education, and fall status. In Model 2, depressive symptomatology was added to the variables in Model 1. Medical conditions (stroke, heart attack, hypertension, and diabetes) were added to variables in Model 3. Models 2 and 3 were performed to test whether high depressive symptoms mediate the relationship between falls and cognitive decline (Model 2) and to test whether the relationship between falls and cognitive decline remains statistically significant after adjusting for all covariates (Model 3). All analyses were performed using the SAS System for Windows, Version 9.2 (SAS Institute, Inc.).

\section{Results}

At baseline, the mean age for the 1,119 participants was 80.8 years (range, 74-109). Sixty percent of the participants were female, $45.6 \%$ were married, and the mean yearsof-education was 6.3 years (range, $0-17$ ). Mean MMSE for the cohort at baseline was 25.2 (range, 21-30). Sixty five percent of participants reported hypertension, $32.9 \%$ diabetes, $14.9 \%$ heart attack, $10.7 \%$ stroke, 5.6\% hip fracture, and $11.9 \%$ had high depressive symptoms at baseline.

Table 1 shows the descriptive characteristics of the sample by fall status at baseline. The prevalence of participants who fell once was $16.6 \%$ and was $14.7 \%$ for those who fell two or more times. The mean MMSE score was $25.5 \pm 3.1$ for no falls, $24.9 \pm 3.0$ for one fall, and $24.5 \pm 2.9$ for two or more falls. The difference was statistically significant between those who fell two or more times and those who did not fall $(P<0.05)$. Participants who fell two or more times were significantly more likely to be older, female, and to report higher levels of depressive symptoms, hypertension, diabetes, heart attack, and stroke compared to those with one fall or no falls. No statistically significant association was seen with hip fracture. Those who fell two or more times had lower performance in handgrip strength when compared with those with no falls $(P<0.05)$. The difference was not statistically significant when compared with those who had one fall. The difference in mean education was not statistically significant across groups.

Table 2 shows the general linear mixed model estimates for MMSE score as a function of fall over a 6-year period. The adjusted rate of decline in the total MMSE score was 0.25 points per year (Model 1). Participants who fell two or more times had a greater decline in MMSE score of 0.81 points per year $(P<0.0001)$ compared with those 
Table I Descriptive characteristics of the sample by fall status at baseline*

\begin{tabular}{|c|c|c|c|c|}
\hline Explanatory variables & $\begin{array}{l}\text { Zero } \\
\text { falls }\end{array}$ & One fall & $\begin{array}{l}\text { Two or more } \\
\text { falls }\end{array}$ & $P$-value \\
\hline Total & 767 (68.7) & $185(16.6)$ & $164(14.7)$ & \\
\hline Age (years) & $80.6 \pm 4.0$ & $81.5 \pm 5.2$ & $81.1 \pm 4.2$ & 0.0157 \\
\hline Sex & & & & 0.0002 \\
\hline Male & $316(4 \mid .2)$ & $54(29.2)$ & $45(27.4)$ & \\
\hline Female & $451(58.8)$ & $131(70.8)$ & $119(72.6)$ & \\
\hline Marital status & & & & 0.0005 \\
\hline Married & $379(49.4)$ & $66(35.7)$ & $63(38.4)$ & \\
\hline Unmarried & $388(50.6)$ & $119(64.3)$ & $101(61.6)$ & \\
\hline Education (years) & $6.4 \pm 3.9$ & $6.3 \pm 4.0$ & $5.9 \pm 3.7$ & 0.3174 \\
\hline MMSE score & $25.5 \pm 3.1$ & $24.9 \pm 3.0$ & $24.5 \pm 2.9$ & 0.0001 \\
\hline Depression (CES-D $\geq 16$ ) & & & & $<0.0001$ \\
\hline Yes & $65(8.5)$ & $30(16.2)$ & $43(26.2)$ & \\
\hline No & 702 (91.5) & $155(83.8)$ & $121(73.8)$ & \\
\hline \multicolumn{5}{|l|}{ Handgrip strength (kg) } \\
\hline Male & $29.4 \pm 7.5$ & $25.7 \pm 7.0$ & $24.6 \pm 6.9$ & $<0.000$ I \\
\hline Female & $18.0 \pm 4.9$ & $17.9 \pm 5.2$ & $16.5 \pm 5.4$ & 0.0192 \\
\hline Hypertension & & & & 0.0002 \\
\hline Yes & $476(62.1)$ & $124(67.0)$ & $129(78.7)$ & \\
\hline No & $291(37.9)$ & $61(33.0)$ & $35(21.3)$ & \\
\hline Heart attack & & & & 0.0017 \\
\hline Yes & $45(5.9)$ & $23(12.4)$ & $19(11.6)$ & \\
\hline No & $722(94.1)$ & $162(87.6)$ & $145(88.4)$ & \\
\hline Stroke & & & & $<0.0001$ \\
\hline Yes & $30(3.9)$ & $19(10.3)$ & $21(12.8)$ & \\
\hline No & $737(96.1)$ & $166(89.7)$ & $143(87.2)$ & \\
\hline Diabetes & & & & 0.0011 \\
\hline Yes & $232(30.3)$ & $60(32.4)$ & $74(45.1)$ & \\
\hline No & $535(69.8)$ & $125(67.6)$ & $90(54.9)$ & \\
\hline Hip fracture & & & & 0.1234 \\
\hline Yes & $20(2.6)$ & $10(5.4)$ & $7(4.3)$ & \\
\hline No & 747 (97.4) & $175(94.6)$ & 157 (95.7) & \\
\hline
\end{tabular}

Notes: $* \mathrm{~N}=\mathrm{I}, \mathrm{I}$ 16. Values displayed as $\mathrm{N}(\%)$ or mean \pm standard deviation.

Abbreviations: CES-D, Center for Epidemiologic Studies Depression Scale; MMSE, Mini-Mental Status Examination.

who did not fall, after adjusting for age, sex, marital status, and education (Model 1). Participants who fell one time had a decline in MMSE score of 0.14 points per year compared to the those who did not fall, but this difference was not statistically significant $(P=0.4261)$. In Model 2 , when high depressive symptoms was added to all variables in Model 1 , the association between two or more falls decreased but remained statistically significant (estimate $=-0.64$, standard error $=0.19, P=0.0007$ ): a decline of 0.64 points per year compared with those who did not fall. In Model 3, after adding medical conditions and hand grip muscle strength to Model 2, the association between two or more falls and MMSE score remained statistically significant (estimate $=-0.46$, standard error $=0.19, P=0.0161$ ): a decline of 0.46 points per year compared with those who did not fall. Female sex, high level of education, and high performance in hand grip muscle strength were associated with a lower decline in MMSE scores.
Figures 1 and 2 shows the unadjusted and adjusted mean distribution for the total MMSE score over the 6-year period by falls status. Participants with two or more falls had lower total MMSE scores than subjects with one fall or no falls over the follow-up period.

\section{Discussion}

We found an approximately $30 \%$ rate of falls in our sample. We also found that, among a cohort of cognitively normal elders, those with history of recurrent falls experienced a greater decline in their cognitive function over a 6-year period compared to those with no history of falls. The fall-cognitive-decline association was independent of age, sex, marital status, and education. Presence of high depressive symptoms partially mediated the relationship between falls and cognitive decline. As expected, and consistent with prior studies, a high level of education and high 
Table 2 General linear mixed model estimates for MMSE score as a function of falls over 6-year period among older Mexican Americans

\begin{tabular}{|c|c|c|c|}
\hline Explanatory variables & $\begin{array}{l}\text { Model I } \\
\text { estimate (SE) }\end{array}$ & $\begin{array}{l}\text { Model } 2 \\
\text { estimate (SE) }\end{array}$ & $\begin{array}{l}\text { Model } 3 \\
\text { estimate (SE) }\end{array}$ \\
\hline Intercept & $27.24(1.62)^{a}$ & $27.42(1.61)^{\mathrm{a}}$ & $24.14(1.75)^{\mathrm{a}}$ \\
\hline Time & $-0.25(0.04)^{\mathrm{a}}$ & $-0.24(0.04)^{\mathrm{a}}$ & $-0.19(0.04)^{\mathrm{a}}$ \\
\hline Age (years) & $-0.05(0.02)^{b}$ & $-0.05(0.02)^{b}$ & $-0.03(0.02)$ \\
\hline Sex (female) & $0.49(0.18)^{b}$ & $0.53(0.18)^{b}$ & $1.04(0.22)^{\mathrm{a}}$ \\
\hline Marital status (married) & $0.29(0.17)$ & $0.21(0.17)$ & $0.26(0.17)$ \\
\hline Education (years) & $0.29(0.02)^{\mathrm{a}}$ & $0.29(0.02)^{\mathrm{a}}$ & $0.29(0.02)^{\mathrm{a}}$ \\
\hline \multicolumn{4}{|l|}{ Falls } \\
\hline None & Reference & Reference & Reference \\
\hline One & $-0.14(0.17)$ & $-0.11(0.17)$ & $-0.08(0.17)$ \\
\hline Two or more & $-0.81(0.19)^{\mathrm{a}}$ & $-0.64(0.19)^{b}$ & $-0.46(0.19)^{c}$ \\
\hline Depression (CES-D $\geq 16$ ) & & $-0.98(0.20)^{\mathrm{a}}$ & $-0.85(0.19)^{a}$ \\
\hline Handgrip strength (kg) & & & $0.05(0.01)^{\mathrm{a}}$ \\
\hline Hypertension & & & $0.16(0.16)$ \\
\hline Heart attack & & & $-0.40(0.26)$ \\
\hline Stroke & & & $-0.07(0.29)$ \\
\hline Diabetes & & & $0.07(0.17)$ \\
\hline Hip fracture & & & $-0.33(0.39)$ \\
\hline$R^{2}$ & 0.12 & 0.14 & 0.20 \\
\hline
\end{tabular}

Notes: $\mathrm{N}=\mathrm{I}$, I 19. All variables were included as time-dependent except age, sex, and education. ${ }^{\mathrm{a}} \mathrm{P}<0.000 \mathrm{I} ;{ }^{\mathrm{b}} \mathrm{P}<0.00 \mathrm{I}$; ${ }^{\mathrm{c} P}<0.0 \mathrm{I}$.

Abbreviations: CES-D, Center for Epidemiologic Studies Depression Scale; MMSE, Mini-Mental Status Examination; SE, standard error.

performance in hand grip muscle strength were found to be associated with a slower decline in MMSE scores.

Our findings are similar to prior studies and different from others. ${ }^{9-12,33-35}$ Most studies have looked at the fallscognition association from the perspective of falls-related brain injury versus no injury as predictors of cognitive decline. ${ }^{3-35}$ Others have studied risks and consequences of falls in the dementia population, or gait disorders as predictors of cognitive decline or dementia, mostly in non-Hispanic populations. ${ }^{36,37}$ Ours is the first study to show that recurrent falls independently predict future cognitive decline in a cohort of community-dwelling Hispanic elders with normal baseline cognitive measure.

It is not clear how recurrent falls predict cognitive decline, but one possibility is a shared risk factor for both falls and cognitive decline (eg, strokes, shared brain network for cognition and gait control, low vitamin D, and brain amyloids). ${ }^{38-41}$ For example, low vitamin D levels are associated with falls, depression, and cognitive impairments. ${ }^{38,39}$ A 12-month prospective cohort study

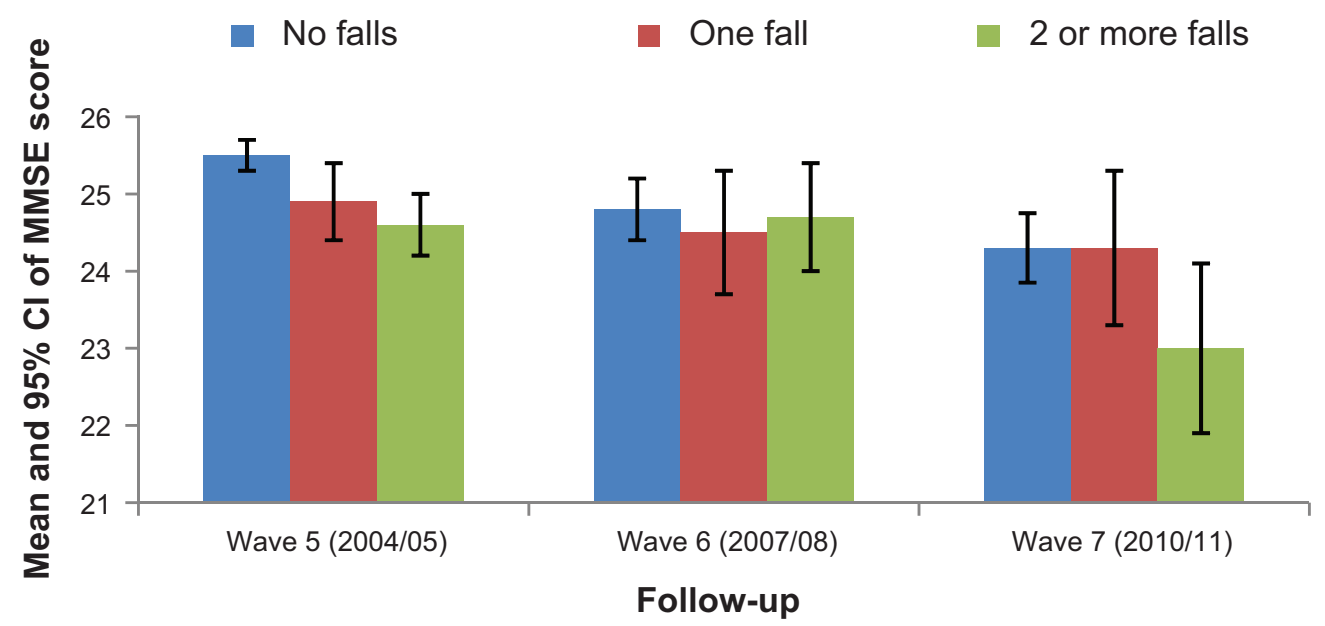

Figure I Unadjusted mean of MMSE as a function of falls over 6 years.

Abbreviations: $\mathrm{Cl}$, confidence interval; MMSE, Mini-Mental Status Examination. 


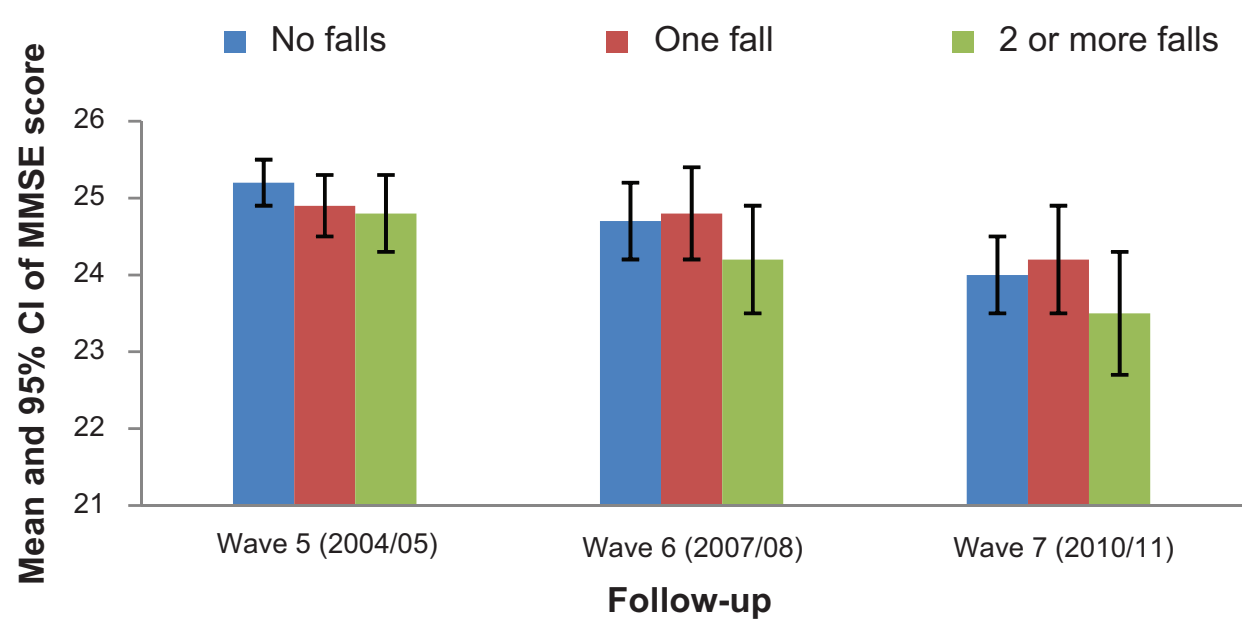

Figure 2 Adjusted mean of MMSE as a function of falls over 6 years.

Abbreviations: $\mathrm{Cl}$, confidence interval; MMSE, Mini-Mental Status Examination.

of cognitively normal, community-dwelling older adults $(\mathrm{N}=125$, mean age $=75$ years $)$ showed that higher levels of brain amyloid (Pittsburgh compound B retention) and of cerebrospinal fluid tau/A $\beta^{42}$ biomarker ratios were significantly associated with increased risk of falls. ${ }^{42}$ These amyloid imaging markers have been well described in persons with mild cognitive impairment and dementia. ${ }^{43,44}$ Lack of amyloid imaging data precludes us from testing the association between amyloid burden and recurrent falls in our subjects with incident cognitive decline. This is an important area for further study, using a combination of amyloid imaging and cerebrospinal fluid biomarker. Were such an association proven, recurrent falls might alert clinicians to patients with high risk of future dementia. Such patients would then be candidates for future preventative intervention.

The literature supports our findings of an association of falls with depressive symptoms and subsequent cognitive decline. ${ }^{1-22,45}$ A 12-year longitudinal study of 2,425 cognitively intact adults showed that high depressive symptoms were associated with accelerated decline in memory, compared to low depressive symptoms as measured with the Center for Epidemiologic Studies Depression Scale. ${ }^{45}$ This association suggests that older adults who fall should be monitored for depression. Early detection and treatment of depression may reduce the progression of cognitive decline.

Another possible explanation for falls-cognitive-decline association is that recurrent fallers are simply sicker than non-fallers, with more conditions (eg, diabetes, heart attacks) that contribute to the MMSE decline seen in recurrent fallers. Our study indicated that recurrent fallers at baseline were more likely than non-fallers to have lower handgrip muscle strength, hypertension, diabetes, heart attacks, and stroke.
Our findings linking falls to cognitive decline still remained significant after adjustment for these conditions. Clearly, efforts to prevent falls-related disabilities require multidimensional approaches to address not just multiple risk factors, but also cognitive, physical, and emotional consequences of falls.

The World Alzheimer Report states that the earlier the diagnosis of dementia, the better the patients' outcome. ${ }^{46}$ Since falls appear to be a predictor of subsequent cognitive decline, health care professionals may be able to detect patients at risk for dementia and implement preventive strategies. Possibilities of such strategies include, but are not limited to, physical activity, Mediterranean diet, and smoking cessation. ${ }^{6,21,26,43,46}$ Clinically, our study also suggests that those who fell, even if cognitively intact, should be screened over time not only for cognitive impairment, but also for emergence of depressive symptomatology, with the expectation that such screening will trigger timely interventions to improve psychological health and reduce future falls.

Depression in fallers could be caused by a fear of having another fall, a syndrome that may be amenable to interventions. After a first fall, the fear of falling increases and could cause an adult to withdraw from activities as a defense against future falls. This activity restriction may manifest as depression. ${ }^{17-20}$ Depression is thought to increase the likelihood of cognitive decline. ${ }^{10,11,47}$ However, caution should be used while prescribing antidepressants to patients who have fallen as studies have shown that these medications cause an increased risk in falling equal to that of untreated depression. ${ }^{16,48}$ Nonpharmacological treatment of these patients may be the most effective option. ${ }^{16}$ 
Our study has several limitations. Generalizability of our findings to other populations is limited because of the low educational attainment ( mean years $=6.3$ ) and advanced age (mean age $=80.8$ years) of our subjects. The H-EPESE data for falls and comorbidities were self-reported, raising the possibility of recall bias, especially if participants have impaired cognition. For this and other reasons, we excluded at baseline participants with poor cognition. We also could not confirm participant self-reports of medical conditions because of unavailability of participants' medical records, radiologic imaging, and blood tests. However, recent studies have validated the reliability of self-reports in studies on fears of falling in cognitively intact and impaired older adults and on barriers to mobility after stroke. ${ }^{49,50}$ The MMSE is used primarily as a screening assessment for cognitive function and has limited sensitivity to detect changes over time, particularly in specialized areas of cognition. Thus, the rate of cognitive decline in our study may tend towards an underestimation. Our study has several strengths: large community-based sample, prospective design, and exploration of the potential role of falls and depression in cognitive disablement in older Mexican Americans (a rapidly growing segment of US elderly population). Another important strength of our study is the use of mixed models, an analytic approach that allowed the use of all available data and evaluation of time-dependent effects.

\section{Conclusion}

In conclusion, having recurrent falls was independently associated with steeper decline in cognition over 6 years compared to having no history of falls, with a mediating effect of depression on the association between falls and cognitive decline. The findings suggest that screening for cognitive and emotional problems in recurrent fallers might help stem the onset of falls-related physical and cognitive disability. Future studies should explore the best way to screen for and treat depression and fear of falling in older adults who have fallen.

\section{Acknowledgments}

Sarah Toombs Smith, PhD, Science Editor and Assistant Professor in the Sealy Center on Aging, University of Texas Medical Branch at Galveston, provided editorial assistance in manuscript preparation. Dr Toombs Smith received no compensation for her assistance apart from her employment at the institution where the study was conducted.

This work was supported in part by the UTMB Medical Student Training in Aging Research (MTSAR) Program,
NIH Grant T35 AG038048, grants R03-AG029959 and R01-AG017638 from the National Institute on Aging, R24-HD065702, Longitudinal Study of Mexican American Elderly Health, NIH Grant AG10939-15 and by the UTMB Claude D. Pepper Older Americans Independence Center Grant P30 AG024832.

Preliminary results of this study were presented as a poster at the 2013 annual meeting of the American Geriatrics Society.

\section{Disclosure}

The authors report no conflicts of interest in this work.

\section{References}

1. Centers for Disease Control and Prevention (CDC). Self-reported falls and fall-related injuries among persons aged $>$ or $=65$ years United States, 2006. MMWR Morb Mortal Wkly Rep. 2008;57(9): 225-229. Available from: http://www.cdc.gov/mmwr/preview/ mmwrhtml/mm5709a1.htm. Accessed March 30, 2014.

2. Centers for Disease Control and Prevention. Web-based Injury Statistics Query and Reporting System (WISQARS). 2005. Available from: http:// www.cdc.gov/injury/wisqars/. Accessed March 30, 2014.

3. Delbaere K, Kochan NA, Close JC, et al. Mild cognitive impairment as a predictor of falls in community-dwelling older people. Am J Geriatric Psychiatry. 2012;20(10):845-853.

4. Hartholt KA, van Beeck EF, Polinder S, et al. Societal consequences of falls in the older population: injuries, healthcare costs, and long-term reduced quality of life. J Trauma. 2011;71(3):748-753.

5. Reyes-Ortiz CA, Al Snih S, Markides KS. Falls among elderly persons in Latin America and the Caribbean and among elderly MexicanAmericans. Rev Panam Salud Publica. 2005;17(5-6):362-369.

6. Tinetti ME, Williams CS. Falls, injuries due to falls, and the risk of admission to a nursing home. N Engl J Med. 1997;337(18):1279-1284.

7. Petersen RC, Smith GE, Waring SC, Ivnik RJ, Tangalos EG, Kokmen E. Mild cognitive impairment: clinical characterization and outcome. Arch Neurol. 1999;56(3):303-308.

8. Ramirez D, Wood RC, Becho J, Owings K, Markides K, Espino DV. Mini-mental state exam domains predict falls in an elderly population: follow-up from the Hispanic Established Populations for Epidemiologic Studies of the Elderly (H-EPESE) study. Ethn Dis. 2010;20(1):48-52.

9. Ferrer A, Formiga F, Plana-Ripoll O, et al. Risk of falls in 85-year-olds is associated with functional and cognitive status: the Octabaix Study. Arch Gerontol Geriatr. 2012;54(2):352-356.

10. Raji MA, Reyes-Ortiz CA, Kuo YF, Markides KS, Ottenbacher KJ. Depressive symptoms and cognitive change in older Mexican Americans. J Geriatr Psychiatry Neurol. 2007;20(3):145-152.

11. Nguyen HT, Black SA, Ray LA, Espino DV, Markides KS. Predictors of decline in MMSE scores among older Mexican Americans. J Gerontol A Biol Sci Med Sci. 2002;57(3):M181-M185.

12. Wang YC, Lin FG, Yu CP, et al. Depression as a predictor of falls amongst institutionalized elders. Aging Ment Health. 2012;16(6):763-770.

13. Raji MA, Ostir GV, Markides KS, Goodwin JS. The interaction of cognitive and emotional status on subsequent physical functioning in older Mexican Americans: findings from the Hispanic established population for the epidemiologic study of the elderly. J Gerontol A Biol Sci Med Sci. 2002;57(10):M678-M682.

14. Biderman A, Cwikel J, Fried AV, Galinsky D. Depression and falls among community dwelling elderly people: a search for common risk factors. J Epidemiol Community Health. 2002;56(8):631-636.

15. Li F, Fisher KJ, Harmer P, McAuley E, Wilson NL. Fear of falling in elderly persons: association with falls, functional ability, and quality of life. J Gerontol B Psychol Sci Soc Sci. 2003;58(5):P283-P290. 
16. Iaboni A, Flint AJ. The complex interplay of depression and falls in older adults: A clinical review. Am J Geriatr Psychiatry. 2013; 21(5):484-492.

17. Painter JA, Allison L, Dhingra P, Daughtery J, Cogdill K, Trujillo LG. Fear of falling and its relationship with anxiety, depression, and activity engagement among community-dwelling older adults. Am J Occup Ther. 2012;66(2):169-176.

18. van Haastregt JC, Zijlstra GA, van Rossum E, van Eijk JT, Kempen GI. Feelings of anxiety and symptoms of depression in community-living older persons who avoid activity for fear of falling. Am J Geriatr Psychiatry. 2008;16(3):186-193.

19. Zijlstra GA, van Haastregt JC, van Eijk JT, van Rossum E, StalenhoefPA, Kempen GI. Prevalence and correlates of fear of falling, and associated avoidance of activity in the general population of community-living older people. Age Ageing. 2007;36(3):304-309.

20. Dias RC, Freire MT, Santos EG, Vieira RA, Dias JM, Perracini MR. Characteristics associated with activity restriction induced by fear of falling in community-dwelling elderly. Rev Bras Fisioter. 2011; 15(5):406-413.

21. Buchman AS, Boyle PA, Yu L, Shah RC, Wilson RS, Bennett DA. Total daily physical activity and the risk of $\mathrm{AD}$ and cognitive decline in older adults. Neurology. 2012;78(17):1323-1329.

22. Bassuk SS, Glass TA, Berkman LF. Social disengagement and incident cognitive decline in community-dwelling elderly persons. Ann Intern Med. 1999;131(3):165-173.

23. Markides KS, Stroup-Benham CA, Black SA, Satish S, Perkowski LC, Ostir GV. The health of Mexican American elderly: selected findings from the Hispanic EPESE. In: Wykle ML, Ford AB, editors. Serving Minority Elders in the Twenty-first Century. New York: Springer Publishing; 1999:72-90.

24. Black SA, Markides KS, Ray LA. Depression predicts increased incidence of adverse health outcomes in older Mexican Americans with type 2 diabetes. Diabetes Care. 2003;26(10):2822-2828.

25. Uhlmann RF, Larson EB. Effect of education on the Mini-Mental State Examination as a screening test for dementia. J Am Geriatr Soc. 1991;39(9):876-880.

26. Johnston B, Yaffe K. Dementia and Delirium. In: Feldman MD, Christensen JF, editors. Behavioral Medicine: A Guide for Clinical Practice. New York: McGraw-Hill; 2008. Available from: http://www. accessmedicine.com/content.aspx?aID=6442112. Accessed December $17,2013$.

27. Cockrell JR, Folstein MF. Mini-Mental State Examination (MMSE). Psychopharmacol Bull. 1988;24(4):689-692.

28. Bird HR, Canino G, Stipec MR, Shrout P. Use of the Mini-Mental State Examination in a probability sample of a Hispanic population. J Nerv Ment Dis. 1987;175(12):731-737.

29. Escobar JI, Burnam A, Karno M, Forsythe A, Landsverk J, Golding JM. Use of the Mini-Mental State Examination (MMSE) in a community population of mixed ethnicity. Cultural and linguistic artifacts. J Nerv Ment Dis. 1986;174(10):607-614.

30. Radloff LS. The CED-S Scale: A self-report depression scale for research in the general population. J Appl Psychol Meas. 1977;1:385-401.

31. Liang KY, Zeger SL. Longitudinal data analysis using generalized linear models. Biometrika. 1986;73(1):13-22.
32. Zeger SL, Liang KY. Longitudinal data analysis for discrete and continuous outcomes. Biometrics. 1986;42(1):121-130.

33. Luukinen H, Jokelainen J, Kervinen K, Kesäniemi YA, Winqvist S, Hillbom M. Risk of dementia associated with the ApoE epsilon4 allele and falls causing head injury without explicit traumatic brain injury. Acta Neurol Scand. 2008;118(3):153-158.

34. Luukinen H, Viramo P, Herala M, et al. Fall-related brain injuries and the risk of dementia in elderly people: a population-based study. Eur J Neurol. 2005;12(2):86-92.

35. Sundström A, Nilsson LG, Cruts M, Adolfsson R, Van Broeckhoven C, Nyberg L. Increased risk of dementia following mild head injury for carriers but not for non-carriers of the APOE epsilon4 allele. Int Psychogeriatr. 2007;19(1):159-165.

36. Buchner DM, Larson EB. Falls and fractures in patients with Alzheimertype dementia. JAMA. 1987;257(11):1492-1495.

37. Verghese J, Lipton RB, Hall CB, Kuslansky G, Katz MJ, Buschke H. Abnormality of gait as a predictor of non-Alzheimer's dementia. N Engl J Med. 2002;347(22):1761-1768.

38. Peterson A, Mattek N, Clemons A, et al. Serum vitamin D concentrations are associated with falling and cognitive function in older adults. J Nutr Health Aging. 2012;16(10):898-901.

39. Wilkins CH, Sheline YI, Roe CM, Birge SJ, Morris JC. Vitamin D deficiency is associated with low mood and worse cognitive performance in older adults. Am J Geriatr Psychiatry. 2006;14(12):1032-1040.

40. Montero-Odasso M, Hachinski V. Preludes to brain failure: executive dysfunction and gait disturbances. Neurol Sci. 2014;35(4):601-604.

41. Alexander NB, Hausdorff JM. Guest editorial: linking thinking, walking, and falling. J Gerontol A Biol Sci Med Sci. 2008;63(12):1325-1328.

42. Stark SL, Roe CM, Grant EA, et al. Preclinical Alzheimer disease and risk of falls. Neurology. 2013;81(5):437-443.

43. Petersen RC. Clinical practice. Mild cognitive impairment. $N$ Engl J Med. 2011;364(23):2227-2234.

44. Bateman RJ, Xiong C, Benzinger TL, et al. Dominantly Inherited Alzheimer Network. Clinical and biomarker changes in dominantly inherited Alzheimer's disease. N Engl J Med. 2012;367(9):795-804.

45. Zahodne LB, Stern Y, Manly JJ. Depressive symptoms precede memory decline, but not vice versa, in non-demented older adults. J Am Geriatr Soc. 2014;62(1):130-134.

46. Prince M, Bryce R, Ferri C. World Alzheimer Report 2011: the benefits of early diagnosis and intervention. London: Alzheimer's Disease International; 2011. Available from: http://www.alz.co.uk/research/ WorldAlzheimerReport2011.pdf. Accessed March 30, 2014.

47. Boyle LL, Porsteinsson AP, Cui X, King DA, Lyness JM. Depression predicts cognitive disorders in older primary care patients. J Clin Psychiatry. 2010;71(1):74-79.

48. Darowski A, Chambers SA, Chambers DJ. Antidepressants and falls in the elderly. Drugs Aging. 2009;26(5):381-394.

49. Robinson CA, Matsuda PN, Ciol MA, Shumway-Cook A. Participation in community walking following stroke: the influence of self-perceived environmental barriers. Phys Ther. 2013;93(5):620-627.

50. Hauer K, Yardley L, Beyer N, et al. Validation of the Falls Efficacy Scale and Falls Efficacy Scale International in geriatric patients with and without cognitive impairment: results of self-report and interviewbased questionnaires. Gerontology. 2010;56(2):190-199.
Clinical Interventions in Aging

\section{Publish your work in this journal}

Clinical Interventions in Aging is an international, peer-reviewed journal focusing on evidence-based reports on the value or lack thereof of treatments intended to prevent or delay the onset of maladaptive correlates of aging in human beings. This journal is indexed on PubMed Central, MedLine,

\section{Dovepress}

CAS, Scopus and the Elsevier Bibliographic databases. The manuscript management system is completely online and includes a very quick and fair peer-review system, which is all easy to use. Visit http://www.dovepress. com/testimonials.php to read real quotes from published authors. 